\title{
Produção Bibliográfica em Turismo no Brasil ${ }^{1}$
}

Margarita Barretto ${ }^{2}$

RESUMO: $O$ artigo levanta o problema da pouca quantidade de livros científicos sobre turismo que são editados no Brasil. Tenta explicar o fato a partir de uma perspectiva sócio-histórica, demonstrando que o hábito de leitura nunca foi muito enraizado no Brasil, que os livros são muito caros e que, ultimamente, a fotocópia tem contribuido para desencorajar tanto os escritores quanto os editores. Propõe algumas possíveis soluções que, juntas, poderiam contribuir para mudar o atual estado das coisas.

PALAVRAS-CHAVE: Turismo e bibliografia; livros científicos; hábito de leitura; Brasil.

ABSTRACT: This article arises the problem of the little amount of scientific books in tourism edited in Brazil, bringing a survey of the available titles in libraries and book stores. It tries to explain the fact from a sociohistorical approach demonstrating that reading never was a spread habit in brazilian society, that books are very expensive and that, lately, photocopy has helped to discourage even more writers and editors. It proposes several possible solutions which could, together, help changing this state of the art.

KEY WORDS: Tourism and bibliography; scientic book; reading; Brazil.

1. Colaboraram naelaboração deste artigo a Biblioteca da Faculdade de Educação daUNIC.AMP, Cleuza Machado(Gerente da Livraria Papinss) e Lucia C. della Tome (aluna do curso de Turismo da Faculdade Ibero-Americana).

2. Bacharel em Turismo. Doutoranda em Educação na Universidade de Campinas. Coordenadora da Coleção Turismo da Editora Papirus.

End. para corresp.: R. José Aparecido Pavan, 650 - Parque das Universidades - 13.086-080-Campinas - SP - Brasil. E-mail:angeli@turing.unicamp.bic. 


\section{Introdução}

A falta de bibliografia para os cursos de Turismo no Brasil é um fato conhecido por professores e estudantes. Os primeiros cursos de Turismo utilizaram bibliografia espanhola e mexicana original e, posteriormente, foram realizada algumas traduções de livros espanhóis e italianos. Na década de 1970 foram editados alguns textos no Brasil, parte deles por editores comerciais, outros por órgãos governamentais e outros, ainda, pelos próprios autores.

Atualmente, a única editora comercial a produzir livros de turismo em série é a Papirus, de Campinas (SP). Duas entidades acadêmicas cditam livros cientificos de Turismo: a Editora da Universidade de Caxias do Sul - Educs e o Serviço Nacional de Aprendizagem Comercial - Senac. Somada a produção das duas, 0 total é de doze títulos, ${ }^{3}$ até 1995.

É preciso discutir os motivos dessa pobreza editorial na área, que obriga a uma predominância da comunicação verbal no ensino de Turismo, com o conseqüiente empobrecimento da linguagem e a efemeridade das informações transmitidas. Nenhuma discussão seria possível sem ter como pano de fundo os componentes da leitura no Brasil, que podem ser divididos, simplificando o esquema dialético de Silva (1985), em Escritor, Obra, Intermediário (editora, livraria, biblioteca) e Leitor.

\section{O Livro no Brasil, um pouco de História}

Enquanto a história da imprensa remonta ao ano de 1445 , em que foi editada a Bíblia de Guttemberg. no Brasil prelos e impressoras ficaram proibidos até 1808 A única forma de fazer um livro era em tipografia, de forma praticamente artesanal, ou imprimindo-o fora do País, como acontecia com o jornal Correio Brasiliense que era impresso em Londres e enviado ao Brasil.

Por outra parte, não existia o hábito da venda de livros, portanto os escritores (mormente poctas) conseguiam publicar seus trabalhos apelando a um mecenas. Nessa procura do que hoje poder-se-ia chamar de "patrocínio", valiam as armas mais sutis, como a registrada por Lajolo \& Zilberman (1991:56) quando, por volta de 1710, Nuno Marques Pereira solicitou ao rico emboaba ${ }^{4}$ Manuel Nunes Viana que 0 auxiliasse na publicação dos seus originais, pois dessa forma obteria graça divina:

Suplico a V. Senhoria, como tāo devoto da Māe de Deus, a quem tenho dedicado este livro se dignem manda-lo ao prelo, e ampara-lo com seu patrocínio para que a mesma Senhora Ihe alcance de seu Divino Fitho mui próspera vida com muito aumento de sua divina graça, como este seu criado the deseja.

3. Não estão incluídos nesta análise os manuais das áreas de Hotelaria e Restaurantes, que são produzidos tanto pela Educs quanto pelo Senac.

作 forasteiros portugueses (...), e, por extensão, aos portugueses em geral." (Ferreira, 1992).
Esse autor, além de revelar grande "talento" negociando com o sobrenatural, demonstra uma relação ambígua da religião com o livro. Com a ajuda concedida, Pereira - para quem o material escrito circulante então era veículo da cultura profana - editou o Compêndio de um Peregrino na América, onde conclamou os leitores a não lerem, dizendo que "melhor é ser caritativo do que ler" (Pereira apud Lajolo \& Zilberman, 1991; 61), o que pode ser interpretado como: a religião católica só via como legítima a leitura de textos sagrados. Uma confirmação disso seriam as memórias do viajante inglês Henry Koster, nas quais relata que, em várias cidades em que viveu, seus vizinhos acharam que ele era padre ou santo porque lia muito.

Alguns dos meus vizinhos... entravam... enquanto eu estava lendo e achavam estranho que eu achasse prazer nessa atividade...um homem dizia: - 0 senhor não é padre, portanto, por quê o Sr. lê? (apud L.ajolo \& Zilberman, 1991: 129)

Essa estranheza da população "nativa" demonstra que a simples carta régia de 13 de maio de 1808, pela qual o Príncipe Regente D. João liberou o uso do prelo, não foi suficiente para a difusão do livro. O público leitor (de literatura "profana") estava concentrado nas classes dominantes da época, como, por exemplo, filhos de fazendeiros residindo na corte, segmento que, por outraparte, nãoera "uma camada culta e elevada, pois preferia o vulgar e o extravagante" (Lajolo \& Zilberman, 1991:65). Para aquelas pessoas, a leitura como prática social era algo superficial. E como se, numa sociedade que aprendesse a ler, a leitura... fosse prenda de salão (Lajolo \& Zilberman, 1991:106).

A implantação da imprensa não só foi tardia, mas também desvinculada de um projeto cultural maior para difusão do hábito de leitura. Este viria apenas com a popularização da escola, o que aconteceu no final do século, com a abolição da escravidão e a nova afirmação do ensino e da ciência surgida a partir da influência do positivismo, que trará ao Brasil a ideologia republicana e o pensamento cientificista.

\section{Relação entre o Livro e a Escola}

Em 1809 a edição de livros de geografia, trigonometria eálgebra sela "desde o início da nossa história editorial a aliança livros-escola"(Lajolo \& Zilberman, 1991:130), mas a escola estava passando por um período de improvisação pedagógica que pode ser testemunhado por um anúncio publicado na Gazeta, do Rio de Janeiro, em 16 de fevereiro de 1920 :

Um sujeito europeu que, tendo-se exercitado nas ciências aritméticas, álgebra, geometria, pilotagem, geografia e história, dá liçỏes em casas particulares, por meio da lingua 
francesa e italiana, e ainda ensina duas trigonometrias sem socorro algum de livros tábuas, escalas, compassos etc. (apud Lajolo \& Zilberman, 1991:132)

Essa precariedade do sistema de ensino também tinha suas raízcs na história colonial. Os esforços educativos da colônia estiveram dirigidos apenas a catequizar indios e a formar bacharéis e sacerdotes, não havendo interesse em educar em massa nem sequer as próprias camadas burguesas.

A catequese dos indios pelos jesuitas resumiu o principal programa educaciona promovido pela administração portuguesa na colônia americana durante os séculos XV e XVII (...) o Estado subsidiava os custos e protegia as escolas (...). Os jovens brancos também precisavam sereducados; contudo, inexistia um sistema escolar exclusivo para eles, que ou assistiam às liçōes dos jesuitas ou permaneciam analfabetos, aprendendo eventualmente a ler, escrever e contar com particulares (...). Já reconhece nesse ponto a pouca (ou quase nula) preocupação das autoridades com a difusão da leitura e escrita, habilidades essenciais aos cidadãos de um Estado que se deseja moderno, como ocorria nos paises europeus, que começavam a investir na educação popular. Assim, a penúria cultural do Brasil, ao longo de todo o periodo colonial (...) decorreu da inexistência de um programa regular de formação da infância, a não ser quando se tratava de prepara religiosos e bacharéis. Que, mesmo nesse caso, precisa bem completar os estudos $\mathrm{cm}$ Portugal (Lajolo \& Zilberman, 1991:27).

Os livros didáticos praticamente não existiram até 1840 e a maior parte deles eram traduções do francês; não havia produção nacional.

Atualmente existe a obrigatoriedade de adquirir livros didáticos para acompanhar as aulas na escola, o que aparentemente seria um dado positivo para a difusão do livro em geral. Na prática, porém, de acordo com os estudos de Silva $(1985 ; 1991)$, o livro didático gera desgosto pela leitura. Para este autor, fundador da Associação de Leitura do Brasil, a qualidade da maior parte dos livros não é boa, desestimulando o estudante, que só lê quando obrigado. Ele vai mais longe, incluindo o professor entre o público não-leitor.

Sempre tendo em mira possiveis exceçōes e o caráter dialético da realidade escolar (...) podemos afirmar que o universo de leitura do professor brasileiro é extremamente restrito (Silva, 1991:25)

Não há estudos sobre a condição de leitura do professor universitário, mas a evidência empírica demonstra que nãoé fácil, atualmente, para um professor (sem outras fontes de renda paralelas), adquirir todos os livros que deveria para sua reciclagem permanente.

\section{O Mercado Editorial}

Em 1820 acabava a censura prévia e em 1821 findava o monopólio do Estado a imprensa. Começava o mercado editorial mas de uma forma descontínua, justamente por não haver um projeto educacional maior que permitisse que as editoras se sustentassem. Os pioneiros foram: a Livraria Universal, dos irmãos Laemmert, fundada em 1833, que priorizava os livros científicos e produzia um almanaque que ficaria famoso; em 1844 inaugurou-se a Garnier Frères, só para venda de livros (não editavam); em 1854 a Livraria Clássica que em 1897 passaria a chamar-se Francisco Alves e que em determinado momento chegou a ter $90 \%$ da sua produção voltada para os livros didáticos

De acordo com Sodré (1981:132) a atividade editorial no âmbito nacional só acontece a partir de 1930, com a industrialização, mas verifica-se o progressivo encarecimento do livro e uma inadequação da forma de distribuição, que privilegia os leitores dos estados do centro-sul. Depois de 1964 retorna a censura e muitas editoras são compradas por empresas dos Estados Unidos que publicam livros e revistas em quadrinhos. As editoras deixam de veicular cultura brasileira para difundir uma cultura totalmente alheia à nossa, objetivando, conforme Sodré (1981), incutir nos jovens as idéias e preconceitos oriundos da "guerra fria".

A falta de interesse em produzir livros evidencia-se na década de 80 , no periodo de vigência da Lei 7505 de incentivo à produção cultural, conhecida como Lei Sarney. Esta lei também aplicava-se à produção de livros, porém "foi nestes onde menos ela foi usada" (Bonclowics, 1991:110).

\section{Os Leitores}

Em 1989 estimava-se que havia uma população de 140 milhões de habitantes no Brasil, dos quais apenas 5 milhões eram leitores. Há outras estimativas de fonte duvidosa que elevariam esse número a 12 milhões, porém não há estudos especificos, apenas estimativas e inferências a partir de outros estudos (Silva, 1993).

Pode-se ter uma idéia da falta do hábito da leitura por parte dos alunos a partir de uma pesquisa realizada nas escolas estaduais do Estado de São Paulo em 1992 , cujos dados revelam que $49 \%$ dos alunos entre a $5^{\text {a }}$ série do $1^{\circ}$ grau e $3^{\text {a }}$ do $2^{\circ}$ grau leêm só de vez em quando, e quando isso acontece suas preferências somam $51 \%$ entre aventura e romance. Os jovens também observam que, tanto seus colegas quanto seus pais e irmãos lêem pouco. Surpreende a pouca aprendizagem residual da leitura, evidenciada pela resposta de $14 \%$ dos jovens que não lembram qual foi o último livro que leram (Secretaria..., 1992).

Verifica-se, outrossim, que os hábitos de leitura dos alunos refletem, de alguma forma, os dos seus mestres: os professores do Estado apresentam, na pesquisa, um comportamento análogo ao dos alunos, pois $38 \%$ preferem ler romances, contra apenas $8 \%$ que lêem textos técnico-didáticos. Por outra parte vê- 
se a falta de incentivo da escola para a atividade de leitura, pois $49 \%$ dos professores declaram não indicar a leitura como atividade obrigatória (Secretaria..., 1992).

Outra pesquisa realizada em âmbito nacional, dentro das familias, revela pouco índice de leitura e traz outro dado interessante: as mulheres são as que mais lêem ( $54 \%$ dos casos), só que o interesse maior é pela leitura de revistas, seguida de livros de literatura, restando para os livros técnicos apenas 3\% (Finep, 1989:119).

\section{O Problema do Preço e da Reprografia}

Os livros são caros no Brasil se comparados aos preços não apenas do México ou Cuba, mas também dos Estados Unidos, França ou, até, da Argentina. De acordo com informıções fornecidas pelas editoras, uma das razões é o preço do papel, e outra a pequena tiragem que o mercado possibilita (3.000 exemplares contra 12.000 que se imprimem nos Estados Unidos). Mas há outra razão que obedece ao conceito de livro enraizado na sociedade brasileira. Nem editores nem leitores aceitam edições em papel jornal (mais amarelado), menos encorpado e que pode ser reciclado). Fecha-se assim o círculo de livros caros para poucos consumidores.

A falta de hábito de leitura da população que, como demonstrado, obedece a razões históricas, somada às dificuldades de relacionamento com o livro no âmbito da própria escola, que teria como um dos protagonistas, também, o professor, a incompatibilidade entre os salários da população e o preço dos livros, e o conceito de livro como artigo "decorativo" são fatores que coadjuvam para desestimular o mercado.

Mas a esses problemas ainda soma-se outro, este sim, mais novo, fruto da nova tecnologia: a fotocópia.

A popularização das máquinas fotocopiadoras, o aperfeiçoamento delas, a diminuição do seu tamanho, tudo concorre para transformá-las num inconveniente à produção de livros.

Nós temos um problema muito grave neste pais, que è o problema da reprografia, a falta de educaçāo no preparo do próprio professor no que diz respeito ao livro. Copiam-se livros ou capitulos inteiros, a nossa educação è feita em base de cópias reprográficas (Bonclowicz, 1991:113).

Em outros paises, como os Estados Unidos, fazer fotocópia de livros é considerado um delito. Dificilmente um operador de máquina copiadora aceitará a tarefa; o que o usuário pode fazer é conseguir uma máquina e fazer a reprodução ele mesmo, arcando com as possiveis conseqüências.

Escrever um livro pode levar anos, e, durante esse tempo (com exceção de alguns escritores consagrados), nenhum autor recebe pagamento algum. A venda do livro é a única possibilidade que o autor tem de recuperar, minimamente, em forma de dinheiro, o tempo investido. Os $10 \%$ que o autor normalmente recebe pela venda do livro é pouco, mas é alguma coisa. Cada livro fotocopiado representa um leitor que não pagará direitos ao autor.

As editoras, por sua parte, investem em digitadores, revisores, desenhistas, fotolitos, pagam registros e impostos; a recuperação desse capital investido faz-se através da venda do livro; da fotocópia nada chega à editora. Quanto maior a quantidade de fotocópias maior o estoque de livros sem vender e maior o tempo requerido para recuperar o investimento. Isto leva a um encarecimento do livro por razão da amortização dos originais e a um desestímulo à produção, tanto por parte do autor quanto por parte do editor.

\section{Livros de Turismo de Autores Brasileiros}

Foi realizado um "survey" à procura de títulos cientificos especificos de Turismo deixando de lado os referentes a lazer e hotelaria, assim como os boletins e relatórios emitidos pela Embratur e institutos oficiais de Turismo dos Estados. Este levantamento não inclui, tampouco, revistas promocionais como Brasilturist, Touristnews, Icaro etc., nem romances ou relatos de viagem. Incluíram-se, sim, estudos de planejamento de organismos oficiais. Realizou-se uma pesquisa nas bibliotecas das Faculdades Anhembi-Morumbi, Capital, Ibero-americana, PucCampinas e USP e em nossoacervo particular, além de um levantamento via fax nas editoras e no sistema Unibibli em CD-Rom que reúne os acervos da USP, Unesp e Unicamp. Foram encontrados 66 livros no total (ver Anexo). Desses, 31 foram editados entre 1970 e 1980 e de 4 não foi possivel estabelecer a data. Apenas 15 foram editados na década de 80, e 23 entre 1990 e 1996.

As editoras comerciais que têm títulos disponiveis até 1996 são: Ática (1), CTI/Terra (2), Hucitec (3), Kosmos (1), Loyola (1) e Papirus (9). As editoras nãocomerciais estão representadas pela Educs (2), a USP (1) e o Senac (2). Constatouse que somente três editoras produzem livros de Turismo em série: Papirus, Educs e Senac.

A quantidade de livros dessas editoras é pequena se comparada com a série da Editorial Trillas, do México, que conta, atualmente, com 45 títulos.

As revistas cientificas também são escassas, destacando-se, praticamente como única produção exclusiva de Turismo com cunho científico, a Turismo em Análise, revista semestral da ECA/USP. A PUC de Campinas tem a Comunicarte (de Comunicações e Artes), também semestral mas publicada com muito atraso, que inclui, em cada número, um artigo sobreTurismo. A revista Chronos da Universidade de Caxias do Sul dedicou, na década passada, o número 9 ao assunto Turismo.

De 1.000 títulos citados por Bercht em 1982 (apud Rejowski, 1993:72) entre livros, folhetos, apostilas, projetos etc. de Turismo e Lazer, encontram-se apenas 12 disponíveis no mercado. Isto não permite concluir que não existam outros livros, apenas que, os que eventualmente possam exisitr, não estão sendo distribuídos para 0 consumidor final. Sobre os livros produzidos na década de 1970 e início de 1980 estão esgotados e não se cogita reedição, apesar da sua alta qualidade, como, por exemplo, os quatro livros de Lourdes Fellini. 


\section{Conclusāo}

A leitura no Brasil é um hábito adquirido na escola, ou imposto por ela, portanto não se pode deixar de vincular a história do livro de turismo no Brasil história dos cursos superiores nessa área. Não é por acaso que os primeiros livro científicos de turismo, aqui produzidos, começaram a ser editados na mesma década do início desses cursos, ou seja, há vinte anos.

Ofato de que os cursos sejam relativamente novos justifica de alguma forma a escassez de livros na área, porém há outras considerações que precisam ser feitas sobre a estrutura desses cursos e o prefil do profissional de turismo.

A maioria dos cursos de turismo está voltada a formar um profissional polifacético capaz de trabalhar em qualquer uma das várias áreas comerciais que o turismo abrange. Poucos são os cursos que formam pesquisadores, que constituem o público leitor por excelência em qualquer profissão.

Muitos dos alunos que procuram os cursos de turismo são, comumente pessoas interessadas em viajar, em organizar eventos, em recreação, enão na leitura de textos científicos. Os professores, por sua vez, aos poucos vão cedendo nas suas exigências, por exemplo deixam de pedir ao aluno que compre livros, porque "o livro é caro"(embora muitos alunos tenham disponibilidade para adquirir outros bens de consumo supérfluos), e, finalmente, rendem-se à cultura da fotocópia para garantir um mínimo de leitura.

Dois grandes paradoxos podem ser observados nessa questão. O primeiro é que os maiores compradores não estão atualmente dentro dos cursos de turismo mas dentro do setor empresarial. O segundo é que, apesar de haver poucos cursos formando pesquisadores em turismo, há ricas teses produzidas em outras áreas, como na comunicação, economia, geografia, ciências sociais, administração ${ }^{5}$. Estas ficam, na sua maior parte, esquecidas nas estantes das bibliotecas univeristárias, sem encontrar editores para a publicação, fato que, em última instância, prejudica o avanço dos estudos científicos de turismo nas próprias faculdades.

Voltando aos elementos do sistema de leitura, escritor, obra, interınediário (editora, livraria, biblioteca) e leitor, pode-se dizer que, no Brasil atualmente, há escritores e obras, mas faltam intermediários e leitores interessados. Apesar do interesse por parte do setor empresarial, parece haver pequena demanda em comparação com outras áreas, o que, provavelmente, torna a produção de livros científicos de turismo desinteressante para os editores.

Acredita-se que a solução esteja, em parte, na edição de livros com custo adequado às condições econômicas dos estudantes e professores, e fundamentalmentena reeducação dos leitores. Como diz Silva (1985), "obem de um livro reside no fato de ele ser 'lido'. Sem olhos que o leiam (...) é apenas papel pintado".

5. A partir dos dados de Rejowski (1993) pode-se estabelecer uma produção de 3,25 teses por ano, no período de 1975 a 1992.
É necessário formar um público que seja leitor de textos científicos de uurismo e é no âmbito acadêmico que isso pode ser realizado. O professor tem a posição privilegiada de conscientizar os alunos, tanto da importância da leitura quanto da dos direitos autorais. É o professor dos cursos de turismo a figura chave que pode mudar o hábito de leitura dos profissionais em potencial e, conseqüentemente, o rumo da produção de livros de turismo no Brasil. Essa conscientização pode ajudar a melhorar a arte da pesquisa e dos estudos científicos de turismo, o que trará, em última instância, beneficios para os próprios cursos, a própria atividade, enfim para a sociedade como um todo.

\section{Referências Bibliográficas}

BONCLOWICZ, A. K. 1989. In: $7^{\circ}$ COLE. Campinas, ABL.

ERREIRA, A. B. de H. 192. Novo dicionáno da lingua portuguesa. 14 reimp. Nova Fronteira.

A

Ha no Brasil. São Paulo: Brasiliense.

(1992). Configuração e sistematização documental. São Paulo, ECA USP. 2 v. Tese de Doutorado.

.

REGIÃO SUDESTE, 3., Unicamp, Campinas.

1991. De olhos abertos. Reflexốes sobre o desenvolvimento da leitura no Brasil. São Paulo: Ática

1993.. Entrevista concedida em 8 nov. UNICAMP.

SODRÉ. N. W. 1981. Sintese de história da cultura brasileira. Rio de Janeiro: Civilizą̧ão Brasileira.

\section{ANEXO}

\section{Listagem dos livros encontrados nas livrarias e bibliotecas de Sāo Paulo e Campinas}

ABELHA, José Flavio. Manual do Turismo Municipal. Belo Horizonte: Imprensa Oficial, 1973, 130 ANDRADE, José Vicente de. Turismo. Fundamentos e dimensões. São Paulo: Ática 1992, 215p. C BERDE, J. J. Godoy. Curso de desenvolvimento para executivos de agências de viagense transportes. São Paulo: CNT, $1974,94 \mathrm{p}$.

D. Duarte. Turismo. Dinàmica social e econômica. São Paulo: Instituto Cultural e Educativo Manuel da Nóbrega, 1982,117 p.

The. Turismo. Fortaleza: Depto. de Estudos Econômicos, 1971, 112 p. BARRETTO, Margarita. Planejamento e organização em turismo. Campinas: Papirus, 1991, 108 p. Manual de iniciação ao estudo do turismo. Campinas: Papirus, 1995, $186 \mathrm{p}$. ONALD, Olimpio. Planejamento e organização de Turismo. Recife: Empetur, 1984 . Teoria e técnica de turismo. Recife: Empetur, 1977.

CASTELLI, Geraldo. Turismo. Análise e organização. Porto Alegre: Sulina, 1975, 184 p. .Turismo. Atividade marcante do século XX. Caxias do Sul: Educs, 1986, 127 p. COSTA, Alfredo, C. M. Algumas reflexöes sobre o turismo na Bahia. Bahia: SCP, 198, $122 \mathrm{p}$ DJURKITCH, Alexandre. Meios de comunicação turistica. Rio de Janeiro: IBet/Cetur, s/d. 50 p. .Modelo alagoano de turismo social. Maceió: Empresa Alagoana de Turismo, 1982, 56 p. DOMIINGUES, Celestino. Dicionário técnico de turismo. Publicą̧ōes Dom Quixote, 1990. MPRESA PARANAENSE DE TURISMO. Turismo no Paraná. Situação atual e perspectivas. Curitiba: Empresa Paranaense de Turismo, 1979, 52 .

FAMA, Rubens. Curso de desenvolvimento para executivos de agências de viagense transportes. São Paulo, CNT, 1974, 28p. 
FELLINI, S. Lourdes. Introdução ao turismo. Porto Alegre: ECS/EST, 1977, 89 p. Turismo. Viabilidade e alternativas. Porto Alegre: EST, 1981, 53 p.

Turismo rural. Porto Alegre: EST, 1981, 52 p.

Turismo. Uma atividade municipal. Porto Alegre: EST, 1983, 79 p.

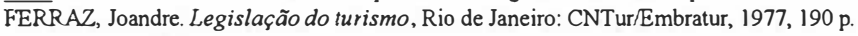
Regime juridico do turismo. Campinas: Papirus, 1992, 162 p.

FUMEST. Ilha Anchieta. Plano geral de exploração turistica. São Paulo: Fumest, s/d.

GOMIDE, M. R. Turismo. Noções elementares. São Paulo: FTD, 1972, 155 p.

HARAS, Francisco. Um estudo para medir a eficácia das medidas de dispersão. São Paulo: SCP, 1977, $17 \mathrm{p}$.

HERNANDEZ PEÑA, D. Turismo. Rio de Janeiro: Organização Bandeirante de Tecnologia, 1974 (4 volumes).

IGNARRA, Luiz Renato. Planejamento tunistico municipal. São Paulo: CTI/Terra, 1990, 83 p.

KERTESZ, Mário. Planejamento na Bahia IV. Bahia: Centro Administrativo da Bahia, s/d. 41 p

LAGE, Beatriz \& MILONE, Paulo. Economia do turismo. Campinas: Papirus, 1991, 122 p.

LEMOS, Amalia Ines G. de. Turismo, Impactos Sócio Ambientais. São Paulo: Hucitec, 1996. 206 p.

LOPES, João do Carmo. T'urismo brasileiro. Análise da permanência dos turistas. São Paulo: IPE(USP)/Embratur, 1983, $133 \mathrm{p}$.

MARTINS, Angelo A. C. Turismo nas Alagoas. Uma alternativa econömica. Maceió: Sergasa, 1991, 178 p.

MINISTÉRIO DE INDÚSTRIA E COMÉRCIO. Turismo. Desenvolvimento turistico do litoral Rio-Santos. Rio de Janeiro: Embratur, 1975, 110 p.

Turismo. Legislação básica. Rio de Janeiro: Embratur, 1970, 349 p.

OLIVEIRA, A. U. de. Geografia turistica do Brasil. Rio de Janeiro: Kosmos, 1988, 241 p. Turismo, a grande indústria. Rio de Janeiro: Kosmos, 1984, 22 Ip.

PAIVA, Maria das Graças Venâncio. Sociologia do turismo. Campinas: Papirus, 1995, 88 p.

PELLEGRINI FILHO, Américo. Ecologia, cultura e turismo. Campinas: Papirus, 1983, 189 p.

PELIZZER, Hilário. Uma introdução à técnica do turismo. Transportes. São Paulo: Pioneira, 1978, 187 p.

PEREIRA, Arlete M. Bibliografia sobre turismo. Rio de Janeiro: Senac, 1988.

PIRES, Luciano Davi. Nova fase do turismo mundial. São Paulo: Eu e Você, 1992.

PORTO FILHO, Ubaldo. Turismo, realidade baiana e nacional. Salvador: Um, 1976.

POZENATO, J. C. Carta de viagem. Caxias do Sul: Educs, 1992.

PUPO, Oswaldo de Aguiar. ABC do turismo e das estäncias. São Paulo: Martins, 1984, 81 p.

RABAHY, Wilson. Planejamento do turismo. Análise economica. São Paulo: Loyola, 1990, 167 p.

REJOWSKI, Mirian. Turismo e pesquisa cientifica. Campinas: Papirus, 1996. 167 p.

Turismo sob a ótica dos monitores municipais. Brasília: Embratur, 1996. 24 p.

RIBEIRO, A.C. Coelho. Estudos conjunturais do turismo no Nordeste. Fortaleza: BNB/Etene, 1976, 35 p.

RODRIGUES, Adłys A. B. Turismo e geografia: reflexões teóricas e enfoques regionais. São Paulo: Hucitec, 1996. 274 p.

RODRIGUES, Gabriel. Fazendo turismo. Cartilha de conscientização turistica. São Paulo: Artes e Texto, 1972,50 p.

RUSCHMANN, Doris. Marketing turistico. Campinas: Papirus, 1991, 124 p.

SECRETARIA MUNICIPAL DE TURISMO DE S.P. Catálogo do cadastro de informações sobre São Paulo. São Paulo: Cebitur, 1976, 227 p.

SECRETARIA DE CULTURA, ESPORTESE TURISMO-SETUR. Subsidios para a estatística brasileira. São Paulo: Secretaria de Turismo do Estado de São Paulo, 1974, 106 p.

SECRETARIADE TURISMOE DESPORTES DERIO GRANDE DO SUL. Consolidação de estudose projetos de Rio Grande do Sul. Rio Grande do Sul: Citur, 1974, 19 p.

SECRETARIA DE TURISMO DE SÃO PAULO. Turismo e esporte. São Paulo: Mauro Ivan Marketing, 1981, 190 p.

SILVA, Ana M. G. da \& BARREIRA, Cristiane A. Turismo de saúde. São Paulo: Senac, 1994, 96 p. (Série Linhas de Pesquisa).

SILVEIRA, J. Xavier da. Turismo. Indústria de base, prioridade nacional. Rio de Janeiro: Record, 1976, 146 p. Turismo. Técnica e operações. Rio de Janeiro: Sedega, 1974, 174 p.

SUDENE. Proposta para um plano diretor de desenvolvimento do nordeste. Recife: Sudene, 1980, $12 \mathrm{p}$.

SUDEPLA. Turismo social e balneário. São Paulo: Sudepla, 1980, 130 p.

SUDEPLA. Possibilidades turísticas no Vale do Ribeira. São Paulo: Sudepla/Seplan, 1974, 176 p.

TRIGO, Luiz Gonzaga Godoi. Turismo básico. São Paulo: Senac, 1995, 88 p. (Série Apontamentos). Turismo e qualidade. Tendências contemporâneas. Campinas: Papirus, 1993, $121 \mathrm{p}$ Cronologia do turismo no Brasil. São Paulo: CTITerra, 1991, 70 p.

$\overline{V A Z}$, Alcides Femandes. Administração de turismo. Rio de Janeiro: ATA, 1975, 354 p.
YAZIGI, Eduardo; CARLOS, Ana F. A.e CRUZ, R. C. Turismo, espaço, paisagens e cultura. São Paulo: Hucitec, 1996. 